and several sites have been examined, including three stone circles, a megalithic tomb, and a series of dwelling sites. The excavations have been carried out under the direction of Prof. Seán P. O'Riordain of the University of Cork. The principal site excavated in 1939 was a large and exceedingly wellpreserved stone circle on the western side of the lake, near the Bruff-Limerick road. Not only is this the best known prehistoric monument of the Lough Gur, but it is also said to be the finest stone circle in Ireland. It is built of large stones backed up by a huge bank of earth, and encloses a level, open internal space $155 \mathrm{ft}$. in diameter.

Here important finds of pottery were made, of which some afford evidence for a new chapter in Irish archæology. A reconstrueted vessel proved to be a 'beaker', the first of its kind to be found in Ireland. It belongs to the class of ceramic characteristic of the 'Beaker Folk', who reached Britain in the late neolithic or Early Bronze ages, but, it has been thought hitherto, did not reach Ireland. A further discovery of considerable interest is that of neolithic pottery of types found only sporadically in Ireland, except in the north-east. On the evidence of the finds, the circle is dated at approximately 1700 B.c., and its ritual purpose, that of a prehistoric temple, is regarded as definitely determined. In a group of neolithic houses on the peninsula of Knockadoon in Lough Gur, one, exceptionally well-constructed, is said to be the earliest house yet found in Ireland. It is $32 \mathrm{ft}$. long by $18 \mathrm{ft}$. wide. The lower part of the walls is of stone, the superstructure of wood and thatch-a type well known from various periods in northern Europe.

\section{Landscape Meteorology}

Mr. L. C. W. Bonacina's paper entitled "Landscape Meteorology and its Reflection in Art and Literature" (Quart. J. Roy. Meteor. Soc., 65, No. 282 ; October 1939) is a detailed study of the scenic aspect of clouds and weather, and an example of that co-operation between science and art which is one of the most interesting developments of culture during recent years. We welcome particularly the author's dictum that it is a mistake for the man of science to regard scenic values as altogether outside his province. It is equally to the point that the landscape artist will find additional enjoyment, and possibly also increased efficiency, if he studies the physics of meteorological effects. The later part of the paper is mainly devoted to descriptions of local and seasonal phenomena. One outstanding example is that of the night sky as seen from the high plateau of Bolivia, where the general aspect of the constellations is that of coloured stars.

Valuable as is this elaborate paper, the reader cannot help feeling how great is the difficulty of bringing the artistic and scientific aspects of a subject into one essay. The perceptive and reflective moods are alternate, and the literary technique for their simultaneous treatment has not been fully mastered. Indeed, we do not yet know if it can be mastered. If so, it will be by Ruskin re-incarnate in the world of to-day, with the same faculties of sight and expression but imbued with the culture of the present time.

\section{Malnutrition in South Africa}

AN informative survey of the state of nutrition of the peoples of South Africa is given by Ellen Radloff and T. W. B. Osborn in a pamphlet with the above title (Johannesburg: The Witwatersrand University Press, 1939. 2s.). South Africa has been spoken of as the most prosperous country in the world, which is a true statement for a minority of the European section. But South Africa is also a country of poor whites and poorer blacks, which is true for several millions of non-Europeans and several hundred thousands of Europeans. The principal dietary essentials for proper nutrition are discussed, with descriptions of the conditions that result when these are deficient. Tables are given of the vitamin content of common foodstuffs and of typical South African diets.

The basic ration scale recommended for adult Europeans at the Health Department's institutions appears to be ample and adequate, and is in striking contrast to the daily diet scale for adult native paupers in Cape Province, which consists of $1 \mathrm{oz}$. of fat (not butter) and $24 \mathrm{oz}$. of mealies. Remedies are suggested for the malnutrition that exists, which include improvement of the economic condition of the people, educating them to buy meat, milk, fruit and vegetables, and in rural communities providing more land for them to buy and improving their grade of cattle. A direct pharmacological approach to the question is also suggested by providing rations of essential salts and vitamins.

\section{Underground-and the City of the Future}

IN the Beama journal of November reference is made to Le Corbusier's city of the future consisting of dwellings, offices, and factories contained in huge blocks separated by gardens. One of the main features of this modern eity is the large part of its activity which takes place underground. Power stations, garages, warehouses and other public service buildings, as well as traffic routes for vehicles and pedestrians, would be constructed in this way. Already there exists a plan for the diversion of a large part of the Paris traffic, the underground routes for which were examined by the Minister of Public Works some years ago. Électricité published a report on this subject by M. Roger d'Arboville, professor of applied electricity in the well-known Ecole spéciale d'Architecture, on the lighting of underground traffic and pedestrian routes. He reviews the pragtice exemplified in some of the short subways in Paris, in the long road tunnel projected for 1941 under the Meuse, the mile-long roadway under the Eseaut at Antwerp and various railway tunnels in France and England.

M. d'Arboville discusses the question of the lighting of underground road tunnels both in actual road tunnels and in many tunnels which are projected. The ever-increasing density and speed of 